$\begin{array}{ll} & \text { Etnográfica } \\ \text { etnográfica } & \text { Revista do Centro em Rede de Investigação em }\end{array}$

Antropologia

vol. $13(1) \mid 2009$

Vol. $13(1)$

\title{
Memórias, histórias e representações sociais do bairro de Vila Isabel e de uma de suas favelas (RJ, Brasil)
}

Memories, stories and social representations of the district of Vila Isabel and one

of its slums (RJ, Brazil)

\section{Fernanda Delvalhas Piccolo}

\section{(2) OpenEdition}

\section{Journals}

\section{Edição electrónica}

URL: https://journals.openedition.org/etnografica/1232

DOI: 10.4000/etnografica.1232

ISSN: 2182-2891

\section{Editora}

Centro em Rede de Investigação em Antropologia

\section{Edição impressa}

Data de publição: 2 maio 2009

Paginação: 77-102

ISSN: 0873-6561

\section{Refêrencia eletrónica}

Fernanda Delvalhas Piccolo, «Memórias, histórias e representações sociais do bairro de Vila Isabel e de uma de suas favelas (RJ, Brasil)», Etnográfica [Online], vol. 13 (1) | 2009, posto online no dia 16 maio 2012, consultado o 11 fevereiro 2022. URL: http://journals.openedition.org/etnografica/1232 ; DOI: https://doi.org/10.4000/etnografica.1232

\section{(c) (†) (8)}

Etnográfica is licensed under a Creative Commons Attribution-NonCommercial 4.0 International License. 


\title{
Memórias, histórias e representações sociais do bairro de Vila Isabel e de uma de suas favelas (RJ, Brasil) ${ }^{1}$
}

\section{Fernanda Delvalhas Piccolo}

\begin{abstract}
A partir da etnografia realizada num Centro Comunitário do Morro dos Macacos, localizado no bairro de Vila Isabel, na cidade do Rio de Janeiro (Brasil), o presente artigo discute a história e a memória do morro e do bairro, explorando alguns eventos realizados nesses locais, que ora reforçam a história e a memória oficiais, ora ressaltam outras versões e memórias existentes e, por vezes, divergentes. Esses eventos interessam como expressões simbólicas dos indivíduos e grupos, ao darem visibilidade às redes de relações, por reforçarem pertencimentos e criarem laços sociais. Importam por contribuírem para a criação de histórias e memórias - oficiais e não-oficiais - que atuam na construção de identidades e representações sociais que, por sua vez, orientam as práticas dos moradores dessas localidades.
\end{abstract}

PALAVRAS-CHAVE: favela, bairro, identidades sociais, memória social, redes sociais, antropologia urbana.

\author{
À minha direita, raia um sol vermelho e branco \\ À minha esquerda, um verde-e-rosa vem dormir \\ À minha frente, ecoa um grito de gol \\ Atrás de mim, dorme a Floresta do Andaraí \\ Entre o Engenho Velho e o Novo ouço cantar \\ Um tangará nas ramas dos oitis do Boulevard \\ Aqui foi que os Drummond, os Rudge e os Maxwell \\ Vieram semear Vila Isabel, vieram semear Vila Isabel \\ Vila, lá vou eu \\ Camisa aberta, ventre livre, chinelo nos pés \\ Da Barão de São Francisco, tomo um chope no Petisco \\ Faço uma fé no Cem Réis \\ Vila, Vila, eu vou \\ Por entre as notas das calçadas musicais \\ Vou seguindo as partituras
}

l Versão de parte da minha tese de doutorado em antropologia social, apresentada ao PPGAS/Museu Nacional/UFrJ, em janeiro de 2006 (Piccolo 2006a), sob orientação do Prof. Gilberto Velho, a quem agradeço as contribuições. Agradeço, ainda, a Ligia Dimitroka pela elaboração do resumo em inglês. 


\author{
De tão sábias criaturas \\ Que fizeram sambas imortais \\ Nossos laços são tecidos \\ Pela flor dos tempos idos \\ Nos antigos carnavais \\ Música Flor dos Tempos de Ruy Quaresma e Nei Lopes
}

\title{
INTRODUÇÃO
}

O presente artigo é fruto de etnografia realizada no Centro Comunitário do Morro dos Macacos, localizado no bairro de Vila Isabel (antiga Fazenda dos Macacos), na zona norte da cidade do Rio de Janeiro (Brasil), no período de agosto de 2002 a janeiro de 2005. ${ }^{2}$ A tese em que tem origem incidiu sobre as redes de relações existentes entre o morro e o bairro, tomando como mote o Centro Comunitário.

Discuto, aqui, a história e a memória do morro e do bairro, explorando alguns eventos realizados nesses locais, como as comemorações de 130 anos do bairro e de 20 anos do Centro Comunitário do Morro, que ora criam e reforçam uma história e uma memória oficiais, ora ressaltam outras versões existentes e, por vezes, divergentes e até concorrentes entre si. Esses eventos interessam como expressões simbólicas dos indivíduos e grupos, pois permitem vislumbrar as redes de relações, reforçam pertencimentos e criam laços sociais entre as pessoas. Dessa forma, atuam na construção de identidades e representações sociais que orientam as práticas dos moradores dessas localidades, cujos aspectos são analisados nesse artigo.

Analisar os processos de classificação, distinção e construção de fronteiras é de extrema importância visto que, no Rio de Janeiro, uma das experiências percebidas e vividas pelos seus moradores como tendo grande potencial para gerar conflitos é a que se refere à relação entre as favelas e a cidade, principalmente entre uma favela e o bairro no qual está inserida (Abreu 1997; Valladares 2005). Esta situação não ocorre apenas no Rio de Janeiro, mas em diversos locais onde haja distintos grupos sociais, com diferentes interesses e visões de mundo e que interajam cotidianamente.

Nesse contexto, cabe atentar para o lugar de Vila Isabel na cidade do Rio de Janeiro, que é uma cidade bastante estratificada e hierarquizada sócio-espacialmente do local de maior ao de menor prestígio e visibilidade: zona sul,

2 Morro, favela e comunidade são categorias nativas utilizadas para fazer referência ao local de moradia das camadas populares, que, neste caso, constroem suas habitações nas encostas de morros. Referem-se ao mesmo local físico, mas ganham diferentes significados, conforme o contexto e o enunciador (Piccolo 2006b). 
zona norte, zona oeste e subúrbio. Na hierarquia social dos bairros e de seus habitantes, a zona sul tem a primazia.

O bairro foi criado no primeiro período de expansão da malha urbana, "determinada, principalmente, pelas necessidades de reprodução de certas unidades do capital, tanto nacional quanto estrangeiro" (Abreu 1997: 43). Ainda segundo Abreu, foram os bondes que possibilitaram a solidificação de uma dicotomia núcleo-periferia. Junto com a criação do bairro, formou-se a Companhia Ferro-Carril de Vila Isabel, ligando o bairro ao centro.

O bairro de Vila Isabel é um importante bairro da zona norte da cidade do Rio de Janeiro. É composto por pessoas das camadas médias e média-baixa, com as camadas populares habitando os morros situados no bairro.

\section{"130 ANOS DE CANTOS E ENCANTOS DA VILA ISABEL": EVENTOS, HISTÓRIAS, MEMÓRIAS E IDENTIDADES SOCIAIS}

Em meados de setembro de 2003, as festividades de aniversário do bairro ${ }^{3}$ de Vila Isabel, comemorado oficialmente em 28 de Setembro, foram anunciadas em duas faixas que cumprimentavam os seus moradores e em dois folders com o cronograma de atividades que ocorreriam durante aquele mês. Essas atividades, concentradas, principalmente, nos dias 26 a 28 de setembro, ocorreram em diversos lugares do bairro. Uma das programações foi organizada pela Subprefeitura da Tijuca e Vila Isabel e a outra pela Prefeitura juntamente com o vereador local. No informativo semanal da Prefeitura também foi anunciada tal comemoração, citando algumas "personalidades" que receberiam uma "condecoração".

Nos folders foram destacados alguns símbolos da identidade oficial do bairro, como o "samba" e a "boêmia", que dão as cores também ao cotidiano dos moradores. É dessa maneira, por exemplo, que Seu Aramias, 80 anos, há 70 morando em Vila Isabel, percebe o local: "é um bairro boêmio".

Num dos folders 4 é ressaltada a constituição do bairro por "famílias, vizinhos e amigos", que, por meio do estabelecimento e reforço dos seus "laços sociais", formam uma totalidade, isto é, o próprio bairro. Esses "laços", que marcam

3 A cidade do Rio de Janeiro está dividida, administrativamente, em Regiões Administrativas e Subprefeituras com vistas a descentralizar a coordenação dos serviços locais e atender às demandas das populações. Cada Subprefeitura é responsável por mais de uma Região Administrativa, que, por sua vez, são compostas por mais de um bairro. Essas instâncias estão subordinadas à Prefeitura Municipal do Rio de Janeiro.

4 "Vila Isabel 130 anos! As famílias do bairro celebram com alegria e orgulho. Aqui toda a cidade se encontra e vamos construindo um ambiente favorável à convivência e à paz em Vila Isabel. Cada um a sua maneira, com sua sensibilidade e sua história. Para nós é valioso que as famílias, os vizinhos e amigos reforcem seus laços mais fortes, que se preservem intactas a cultura e a simbologia das nossas ruas e que se mantenha a mística que o nome do bairro sempre teve. Vila Isabel é responsabilidade nossa. Com vida e alma" (excerto do folder organizado pelo vereador). 
pertencimentos, podem ser vistos como formando redes de relações sociais. Assim, a "cidade se encontra" no bairro, mas não qualquer pessoa da cidade, somente aquela que se torna "família, vizinho e amigo", visto que somente entre conhecidos é possível construir "um ambiente favorável à convivência e à paz" no local. Esses "laços" são tecidos numa "cultura" e numa "simbologia" que os indivíduos e instituições que as constroem e as oficializam não pretendem modificar, mas, sim, desejam que sejam "preservadas intactas". Por isso, é de fundamental importância comemorar o aniversário do bairro e recordar, reafirmando qual história, qual "cultura" e quais "símbolos" oficialmente se pretende manter com "vida e alma".

No outro $f_{0} l d e r^{5}$ é ressaltada a musicalidade, trazendo à memória músicos com projeção nacional que seriam originários do bairro. A música, seus compositores e intérpretes, como símbolos e produtores da identidade local, foram cristalizados, ainda, em monumentos, como as "calçadas musicais" e estátuas de Noel Rosa, situadas na entrada no bairro (via centro da cidade) e em outros locais. ${ }^{6}$ Como aponta Pollack (1989: 10), estes monumentos concorrem para o "trabalho de enquadramento" da memória, pois neles "a memória é assim guardada e solidificada nas pedras".

Nascimento, vida e morte aos 26 anos (em 1937) do músico e compositor Noel Rosa ${ }^{7}$ evocam o samba e a boêmia e marcam a identidade oficial do bairro. Para os moradores, esta musicalidade seria um sinal diacrítico do bairro, expresso na utilização de títulos de músicas desse compositor nos nomes de bares e lojas comerciais, de um túnel e de um edifício no bairro. A fala de Dona Antônia, 56 anos, evidencia a visão boêmia do local e personifica Noel Rosa na "estátua" do compositor, que, para ela, virou "um ponto de turismo":

Vila Isabel é um lugar muito bom pra se morar, todo mundo quer morar em Vila Isabel, na terra de Noel! [...] A gente sempre escuta as músicas do Noel Rosa quando ele faz anos, vou na praça, faz aquela festa. [...]

5 "130 anos de cantos e encantos da Vila! Reduto da boa música e da boêmia carioca, o bairro de Vila Isabel chega aos 130 anos e se mantém inspirador e vanguardista. Cenário de ricas histórias, o bairro de Noel, Martinho da Vila e de tantos outros mestres... ainda Canta e Encanta seus moradores e freqüentadores." (excerto do folder da programação da Prefeitura e Subprefeitura)

6 Em 1964 foram construídas, no passeio da principal avenida do bairro, as "calçadas musicais" um mosaico de pedras brancas e pretas com partituras de músicas de Noel Rosa e outros compositores. Um dos monumentos em homenagem a Noel Rosa, o do início desta mesma avenida, está em cartões postais e num ímã de geladeira presenteado por ocasião dos 130 anos do bairro, mandado confeccionar por um vereador, o que pode ser entendido como um esforço para tornar a obra um símbolo local.

7 Noel Rosa é um importante artista da música popular brasileira, reconhecido, entre outras coisas, por realizar a união do samba feito no morro com aquele feito no "asfalto", de onde ele era originário. Noel Rosa, branco e das camadas médias contribuiu, dessa forma, para a popularização do samba, colocando-o nas rádios. Cabe ressaltar que o samba, no período em volta de 1920 e 1930, era marginalizado. 
Lá depois do [hospital] Pedro Ernesto tem um busto do Noel Rosa: "Seu garçom faça o favor de me trazer depressa" [trecho da música Conversa de Botequim, de Noel Rosa e Vadico], ele está sentado e o garçom servindo ele, ele é o Noel Rosa. [...] ali é um ponto [de] turismo, muita gente freqüenta aquele pedaço ali.

A música tem papel importante na manutenção da memória do grupo, pois, sendo gravada e registrada, torna-se um documento que permanecerá mesmo após a morte daqueles que a compuseram.

Em diversas músicas de Noel Rosa, hoje cantadas e ouvidas, os temas da musicalidade do bairro e de sua rivalidade com outros bairros e morros, principalmente aqueles que inspiram os compositores, são trazidos à tona, tal como acontece nos seguintes versos: "Fazer poema lá na Vila é um brinquedo/ Ao som do samba dança até o arvoredo/ [...]/ A Vila é uma cidade independente" (música Palpite Infeliz de Noel Rosa, 1936).

Outro tema presente nas músicas e na história oficial do bairro é o fato de a "Princesa Isabel" ter emprestado o nome ao bairro: "São Paulo dá café, Minas dá leite e a Vila Isabel dá samba/ [...] Tendo o nome de princesa transformou o samba/ num feitiço decente que prende a gente" (música Feitiço da Vila de Noel Rosa e Vadico, 1936).

Esses elementos aparecem ainda na letra da música que apresento como epígrafe deste artigo, Flor dos Tempos, gravada em 1984 por Martinho da Vila; ${ }^{8}$ ao mesmo tempo que atuam na construção da identidade local, legitimam o músico, que nasceu em um bairro vizinho à Vila Isabel, como representante do bairro. Assim, como frisou Seu Aramias, "apesar dele [Martinho da Vila] não ser daqui", ele "adotou" o bairro e tornou-se, segundo Seu Mariano - 68 anos, morador do bairro e presidente da entidade carnavalesca Banda ${ }^{9}$ de Vila Isabel -, "[...] um ícone, vamos dizer assim, de Vila Isabel. A figura mais representativa que nós temos hoje, em Vila Isabel, é o Martinho da Vila. [Ele] é uma unanimidade nacional".

$\mathrm{Na}$ música é expressa a identidade construída para o bairro, que toma, ainda, a Escola de Samba como um de seus pilares. É neste sentido que "cantar o espaço não significa meramente reproduzi-lo, mas, sobretudo, criá-lo. A música é, pois, submetida a uma identidade" (Sulpino 2002: 111 ). Ela é um símbolo pelo qual a sociedade se traduz (no sentido de comunicar), reforçando uma identidade e demarcando a alteridade (Lucas 1994).

8 Martinho da Vila é um importante sambista, intérprete e compositor no cenário atual brasileiro; é presidente de honra da Escola de Samba Unidos de Vila Isabel.

9 No Rio de Janeiro há diversas entidades carnavalescas, entre as quais os blocos, as bandas, como a Banda de Vila Isabel, e as escolas de samba. Os blocos são organizações menores e as escolas de samba possuem uma estrutura administrativa mais complexa. 
Na música em epígrafe, além da localização do bairro e da Escola de Samba, surgem referências a espaços de sociabilidade, que construiriam os "laços" entre seus moradores, reforçando o sentimento de pertencimento.

Um desses espaços é um bar/restaurante situado numa das esquinas da avenida principal. O local é um dos principais pontos de encontro de um grupo expressivo no bairro, constituído, em sua maioria, pelas camadas médias, que se reúnem nos finais de semana, nos fins de tarde e numa série de eventos, tais como o "Dia do 171 ", ${ }^{10}$ ou quando são apresentados grupos musicais. Este bar/restaurante, como outros estabelecimentos próximos, coloca mesas e cadeiras nas calçadas, que permanecem lotadas durante os eventos. Nessa esquina é realizada a concentração e o ponto de partida dos ensaios técnicos da Escola de Samba Unidos de Vila Isabel.

Nesse contexto, o evento de comemoração dos 130 anos do bairro ganha significado por sua colaboração na construção e manutenção da memória coletiva e oficial, mediante a teatralização da história que foi oficializada, necessária à preservação (e construção) das identidades sociais (Portelli 1998; Silva 2002).

Abordar o tema da história - e de suas comemorações - tem a ver com a forma como a memória é construída, com qual memória está sendo preservada e de que maneira, dado que ela é relacional e seletiva (Halbwachs 1990; Costa 1999). Nesse sentido, a história oficial, relembrada nas comemorações, preserva uma memória oficial das instituições e celebrações dos grandes feitos e dos grandes homens, tal como foram cristalizadas em livros, ${ }^{11}$ numa vasta literatura publicada sobre o bairro e expoentes gabaritados. ${ }^{12}$ Essa produção de livros, como aponta Leroi-Gourhan (1983), faz parte de uma memória material que, por meio de fichários e bibliotecas, "guarda" a memória coletiva, tornando-se um recurso a ser acessado a qualquer momento.

A história oficializada fixa uma versão dos acontecimentos, aquela contada e escrita por grupos que detêm meios e poder para fixar sua visão de mundo, veiculada por meio de obras bibliográficas que tornam hegemônica essa história, sem problematizar ou levar em consideração a coexistência de outras versões tão "verdadeiras" e significativas quanto a que se tornou institucionalizada.

10 Este evento realiza-se no dia 17 de janeiro e é organizado pela Banda de Vila Isabel. Nele é eleito o "17 l", isto é, a pessoa mais "malandra", "pilantra", "contador de estórias" do bairro. Esta brincadeira é uma referência ao Código Penal Brasileiro, no qual o artigo 171 define o crime de estelionato.

11 Os livros a que me refiro são: Borges e Borges (1987); Anuário de Vila Isabel 95 (1995); Blanc (1996); Aragão (1997); Gaspar (2003). Ainda sobre a história de Vila Isabel, ver, entre outros, Gerson (1959). Há, ainda, uma produção musical construindo essa história. Sobre Noel Rosa e seus parceiros musicais, ver, entre outros, Máximo e Didier (1990).

12 No caso, aqui, o subprefeito da Tijuca e Vila Isabel, o bisneto daquele a quem é atribuída a fundação do bairro - o Barão de Drummond -, ou um poeta reconhecido no bairro, entre outros, isto é, alguns moradores, do passado e do presente, vistos como representantes dessas instituições. 
A distinção entre memória oficial e não oficial informa diferentes representações dos acontecimentos. Essas histórias e memórias, aqui narradas, ora reinventadas, ora reforçadas, interessam pelas representações que carregam e pululam no cotidiano dos moradores. $\mathrm{O}$ evento, ainda, confere visibilidade às redes sociais, nas quais essa história é reproduzida.

A cerimônia de abertura das comemorações foi realizada no dia 26 de setembro de 2003, no auditório do Instituto Pão de Açúcar, situado no pátio de um supermercado. ${ }^{13}$

Enquanto eu esperava a abertura do auditório, iniciei conversa com um casal de idosos acompanhados por uma outra senhora. As duas mulheres eram irmãs e moram no local há 53 anos. O casal me disse: "foi aqui onde tudo começou, no Jardim Zoológico e na Fábrica Confiança”. Falaram, ainda, sobre sua participação no evento: "nós viemos prestigiar, a gente mora no bairro". As irmãs ouviram o anúncio da comemoração, nesse dia, no "carro de som" que circulava pelas ruas e num canal de televisão.

No desenrolar do evento percebi que a platéia era composta, principalmente, pelos familiares e amigos dos jovens membros da Orquestra Pão de Açúcar (que é um dos "projetos sociais" do Grupo Pão de Açúcar), que se apresentou, por aqueles que seriam homenageados e seus familiares, por funcionários da Subprefeitura e por outros (poucos) moradores do bairro, que vieram "prestigiar" o evento.

Alguns minutos após entrarmos no auditório, o subprefeito da Tijuca e Vila Isabel chegou, saudou, cumprimentou e agradeceu a presença de todos. Alguns meses mais tarde, eu o reencontrei em dois ensaios do Bloco Balanço do Macaco, na quadra da escola pública estadual no morro. Nesses ensaios ele estava na posição de patrocinador do bloco. Segundo o presidente do bloco, o patrocínio incluiu, ainda, o churrasco que acontecia junto ao ensaio e do qual participavam, principalmente, os integrantes da bateria e seus dirigentes. Nas eleições municipais de 2004 ele foi eleito vereador.

No interior do auditório, pouco depois, a anfitriã, diretora do Instituto Pão de Açúcar, subiu ao palco e deu abertura ao evento, referindo-se ao bairro de Vila Isabel como um "bairro histórico", que tem "tradições, mitos, lendas, orgulho". Por fim, publicizou a atuação da empresa no campo social, apresentando o trabalho desenvolvido na "área social, de educação para crianças e jovens", tendo como objetivos "a transformação da sua vida, da sua família e, esperamos também, da sua comunidade”. Sua fala remete às ações que são empreendidas por empresas no âmbito das políticas de "responsabilidade

13 O supermercado e o Instituto Pão de Açúcar pertencem ao Grupo Pão de Açúcar, uma rede varejista nacional, e ocupam as instalações que pertenceram à Fábrica de Tecidos Confiança, inaugurada em 1885 e mantida em funcionamento até 1964 (Borges e Borges 1987). 
social". Essas ações podem ser consideradas civilizatórias, porque pretendem "transformar" a vida das pessoas, por meio da "educação". ${ }^{14}$

No evento, ocorreu, depois, a apresentação teatral da dupla "As Velhas da Vila", que contaram e encenaram a história oficial do bairro. Os atores, dois homens representando duas "velhas", com 130 anos, usando vestido comprido, perucas brancas, óculos e maquiagem, encarnavam a idade e traziam à memória a história de Vila Isabel, numa linguagem cômica como recurso de fixação dessa memória. Embora o evento não tenha sido visto e ouvido por todos os moradores do bairro, os folders e a programação que teve lugar nesse período também contribuíram para a circulação e o reforço dessa história. Dessa maneira, a peça teatral participou do trabalho de construção de uma memória coletiva, tendo como base a história oficializada. A narrativa foi iniciada ressaltando a musicalidade e a "beleza" local, da seguinte maneira:

Em 3 de janeiro de 1872, a Vila Isabel quando nasceu, não nasceu chorando, já nasceu cantando. Era a Fazenda do Macaco, lugar tão belo e tão exuberante que Dom Pedro deu de presente para a princesa Amélia, sua segunda esposa. Antes de ser vila foi uma princesa.

Na história contada, a dupla ressaltou que o bairro seria o primeiro bairro residencial planejado da cidade, projetado a pedido do Barão de Drummond, que hoje empresta o nome à principal praça do bairro, conhecida e ainda chamada por muitos moradores de Praça Sete [de Março], em alusão ao antigo nome oficial (Gerson 1959).

O bairro se chamaria "Vila Isabel em homenagem à Princesa Isabel", pelo fato de esta ter sancionado a Lei do Ventre Livre. As primeiras ruas do bairro ganharam seus nomes devido à honraria que teria sido prestada ao movimento abolicionista. Durante o evento, o bisneto do Barão de Drummond distribuiu um folheto com a cópia da Lei do Ventre Livre, com uma menção a essa deferência: "O Barão de Drummond, deliberadamente, ao criar em sua fazenda, o novo bairro (1873) consagrou a Lei do Ventre Livre em seus nomes, no Boulevard, nas ruas, transformando Vila Isabel em monumento do ideal abolicionista, fato histórico que se comemora em 2003."

A data da assinatura da Lei do Ventre Livre, 28 de setembro, tomada como a data oficial de aniversário do bairro, foi a escolhida dentre outras possíveis,

14 As políticas de "responsabilidade social" das empresas são motivadas pela internacionalização da economia e surgidas "num contexto no qual há uma crise mundial de confiança nas empresas" (Rico 2004: 74). Segundo Costa (2003: 148), as empresas implementam ações sociais e uma "gestão participativa", almejando "aumentar a produtividade de seus empregados e torná-los mais comprometidos com o trabalho" e ainda "obter o reconhecimento da sociedade em relação aos projetos sociais das empresas", que estariam "preocupadas com a questão ambiental, a saúde, a educação, a cultura, etc., que assumem, assim, parcelas da dívida social”. 
como: 3 de janeiro de 1872, a data do projeto; 6 de março de 1873, quando a planta urbanística foi aprovada; fevereiro de 1874, época em que os primeiros lotes foram vendidos. Essas datas dão origem a outras versões sobre a criação do bairro, pois, segundo Borges e Borges (1987), a data do projeto seria a "data verdadeira da criação do bairro".

Para Seu Aramias, a data comemorada, "28 de Setembro, não tem a ver com o dia de fundação da rua e do bairro", que, segundo ele, seria " 4 de abril". No entanto, "resolveram" deixar como a data de aniversário o dia em que foi assinada a lei segundo a qual todos os filhos nascidos de escravos seriam "livres", "embora haja controvérsias", como assinalou. Essas "controvérsias" colocam em jogo a memória e a história oficial construída para o bairro.

Com o desenvolvimento da narrativa histórica dramatizada pelas "Velhas da Vila” eu me lembrava, especialmente, de dois livros sobre Vila Isabel. Parecia que eu estava vendo diante de mim a encenação dos livros, pois a história narrada é a mesma escrita, demonstrando o esforço para "manter intactas a cultura e a simbologia" do bairro, isto é, o esforço de manutenção e preservação da memória e da história institucionalizadas. Os livros são: A Vila de Isabel e Drumond a Noel (Borges e Borges 1987) e Vila Isabel: Terra de Poetas e Compositores (Aragão 1997). O primeiro livro, de acordo com os autores, pai e filha, moradores de um bairro vizinho, foi escrito com a intenção de "recuperar e divulgar a história de Vila Isabel”. Já o segundo é praticamente uma síntese do primeiro, acrescidos os interesses de divulgação de "personalidades" que são vistas pela autora ${ }^{15}$ como merecedoras de destaque por sua atuação no bairro. São "personalidades" que entram para a história oficial e serão recordadas, tanto no evento como posteriormente, quando o livro for lido e, talvez, na memória dos indivíduos já tenham sido esquecidos. Nesse sentido, a publicação é também um esforço contra o esquecimento. Os dois livros, dentre outros publicados, registram, marcam e cristalizam uma memória e uma história, são institucionalizados e tornam-se documentos (Pollack 1989).

Depois de narrar a história institucionalizada, passaram à "cerimônia de entrega das comendas" para as "personalidades" do bairro. Para condecorarem as personas Barão de Drummond, Bittencourt Silva (que projetou o bairro) e a Princesa Isabel, a dupla escolhia aleatoriamente pessoas na platéia e lhes entregava uma insígnia; essas pessoas passavam, então, momentaneamente, a ser a representação daquelas (Mauss 1999 [1929]).

A dupla trouxe à memória Noel Rosa, Martinho da Vila e os sinais diacríticos da identidade local: "A Vila da boêmia, a Vila do samba nunca vai acabar, está cada vez mais bamba." Enquanto falavam, fizeram duas apresentações de samba, com marionetes, ao som de músicas de sambistas locais. 
Ainda durante a cerimônia, o subprefeito da Tijuca e Vila Isabel proferiu seu discurso e exaltou os símbolos da identidade oficial do bairro: "São muitos os cantos e encantos da Vila; o berço da boêmia carioca; do chope, samba e batucada." Citou os elementos que teriam feito parte da história local: "índios, escravos, jesuítas, nobreza imperial; Barão de Drummond e Noel Rosa". Recordou a cristalização da "memória e identidade cultural" citando monumentos do patrimônio histórico. E fez uma prestação de contas, enumerando as ações realizadas pela Prefeitura e pela Subprefeitura na região. O evento, dessa maneira, além de contribuir para a manutenção e preservação da história e da memória oficiais, estava inserido na arena política, com a promoção das ações do poder público municipal.

O subprefeito anunciou, ainda, que tinha uma "missão muito especial", a de "fazer homenagem a um time de primeira, pessoas que enriqueceram a vida cultural do bairro", e passou à entrega do troféu e do diploma de "cidadão vilaisabelense" àqueles considerados "merecedores" deste título. Os premiados, com exceção da presidente do Centro Comunitário Maria Isabel, constam no livro de Aragão (1997). O merecimento está atrelado ao papel desempenhado por essas pessoas na construção e manutenção da história e da memória tidas como "verdadeiras" pela Prefeitura. Além disso, elas constituem pontos nodais de redes sociais que perpassam as relações com a Prefeitura, com a empresa anfitriã e entre os próprios condecorados.

Cada homenageado, após receber o troféu e o diploma, agradecia ao público e às instituições organizadoras do evento e recordava algo marcante para o bairro. Receberam o prêmio consecutivamente: o bisneto do Barão de Drummond, anunciado como a pessoa que contribui para a "preservação da memória, [pois] tem documentos valiosíssimos: a cópia da lei e do documento de compra da Fazenda [do Macaco]"; um poeta local, apresentado como "uma referência para o bairro, [pois] contribuiu para o fortalecimento da história do bairro", que agradeceu declamando uma poesia de sua autoria. ${ }^{16}$

$\mathrm{Na}$ poesia declamada é marcada uma posição ufanista ${ }^{17}$ diante do bairro, é expressa a distinção e a rivalidade com outros lugares, por "ter tudo o que a mim convém", isto é, as "canções" e a musicalidade, que fazem de Vila Isabel um "mundo fechado em si" e que causa "inveja" a outros locais.

16 Esta poesia encontra-se também no livro de Aragão (1997): "Meu bairro tem/ tudo que a mim convém/ Ele é meu mundo,/ É o meu amor profundo/ Eu não invejo o de ninguém,/ Pois o que eu quero/ meu bairro tem:/ Garotas lindas a passear/ Pelas calçadas sem esnobar,/ Mostrando a todos/ Que aqui vêm/ Que tudo isto meu bairro tem./ Tem tradições de invejar,/ muitas canções para se cantar,/ samba no chão que ninguém tem,/ Mas tudo isso meu bairro tem./ E quem quiser vir comprovar,/ Basta andar no Boulevard./ Meu bairro é a capital/ Deste país tão musical,/ Meu bairro é pra mim um céu,/ Seu nome é Vila Isabel".

17 Ufanista é aquele que se orgulha, inclusive em excesso, de algo, como sua nação, seu bairro. 
Outro morador, Seu Mariano, ressaltou os sinais diacríticos do bairro na entrevista que me concedeu alguns meses após este evento. Em seu relato, a identidade e as fronteiras construídas assentam na "boêmia", no "samba" e nos "encantos" locais. A "diferença" foi sinalizada quando afirmou que todos os moradores se "conheceriam" e agiriam unidos, seriam solidários em prol das "causas sociais" locais. E, ainda, o bairro teria "vida própria", seria "completo".

A terceira condecorada foi, in memoriam, a escritora e proprietária da editora Conquista, representada por sua filha; a quarta, a presidente do Centro Comunitário Maria Isabel, do Morro Parque Vila Isabel, que representaria as favelas locais - favelas estas que, assim como sua representante, não fazem parte da história e da memória oficializada nos livros e documentos produzidos em torno do bairro. Ela foi a única pessoa que não compareceu nem enviou representante. Alguns dias depois, no Centro Comunitário, comentei com ela sobre sua ausência no evento. Ela disse-me que não foi porque "tinha uma reunião do Comitê Contra a Fome" na Igreja Batista que freqüenta.

O quinto condecorado foi o presidente da Escola de Samba; o sexto, o sambista Martinho da Vila; o sétimo agraciado foi um pesquisador, escritor, compositor e intérprete representado no evento por um amigo, que disse: "ele adotou esse bairro com muita honra e muito carinho”. Mediante a premiação a estes dois últimos personagens é possível perceber que a pertença à "comunidade" de Vila Isabel não está atrelada àqueles que nasceram no bairro, mas à “adoção" do bairro, ou melhor, dos valores e práticas pelos quais o bairro é representado, tanto internamente como para além de suas fronteiras. Por fim, recebeu a homenagem um empresário local, o proprietário daquele bar/restaurante, ponto de sociabilidade local, como mencionado acima, e de outros negócios, que também enviou uma pessoa para representá-lo.

Por intermédio dos "homenageados", a história e a memória oficiais foram atualizadas, sua origem foi reafirmada por meio da condecoração do bisneto do Barão de Drummond, sua identidade foi reforçada pela honraria dada ao poeta, ao sambista e àqueles que a reproduzem - o pesquisador e a editora -, a dinâmica econômica foi ressaltada pela homenagem ao empresário e pelo próprio local onde estava acontecendo o evento, ao mesmo tempo que foi trazida para a rede de relações a presidente de uma das entidades do morro.

Terminando o evento no auditório, o subprefeito agradeceu aos "parceiros" da arena política, que marcaram e distinguiram redes de relações sociais que ora se atravessam, ora se encontram.

Após esta cerimônia, ocorreu um coquetel e um show de música popular, num outro espaço do Instituto Pão de Açúcar. Lá, conversei com alguns moradores do local. Uma das pessoas me orientou: "muita coisa que falaram ali sobre a história de Vila Isabel estava errada, você tem que pesquisar mais". Sua ressalva aponta para a coexistência de memórias e histórias não oficiais, que divergem e podem mesmo concorrer com a oficial. 
No dia seguinte, sábado 27 de setembro, as comemorações de aniversário do bairro continuaram na praça central. Paralelamente, ocorria a festa de São Cosme e Damião, ${ }^{18}$ organizada pelos integrantes da Banda de Vila Isabel para as crianças da "comunidade", como me disse seu presidente:

- Por que vocês fazem a festa de São Cosme e Damião?

- Isso foi uma idéia minha, foi uma promessa que eu fiz, que Vila Isabel, a comunidade do Morro dos Macacos, do Pau da Bandeira, essa região aqui que circunda o bairro de Vila Isabel tem muita gente pobre, sabe? Então, eu fiz uma promessa, que o meu neto ele foi operado do cérebro e eu fiz uma promessa que todo dia festivo de São Cosme e Damião eu daria 50 ou 100 saquinhos de doce para as crianças e passei essa idéia para o pessoal da Banda, eles assimilaram bem.

Os membros da banda são majoritariamente "brancos", de classe média e moram no bairro: "nós temos até general da reserva que desfila na banda; militar, temos médicos, engenheiros [...], comerciantes, tem até político no meio, como sócio da banda" (Seu Mariano). Os participantes da festa eram, na maioria, moradores das favelas locais.

$\mathrm{Na}$ festa, algumas mulheres, integrantes da banda, preparavam cachorros-quentes e os homens serviam refrigerantes em copos plásticos, distribuídos aos participantes da festa que, em fila, esperavam sua vez de receber. No meio da rua havia uma "carrocinha" de pipocas e um casal fazia a distribuição em saquinhos aos que, em fila, aguardavam. Próximos da "carrocinha" foram montados três grandes brinquedos para as crianças.

Entendo que é neste contexto que falas como a de Dalila, moradora do bairro, ganham sentido: "Vila Isabel é um bairro muito comunitário, muito familiar".

Eventos como a festa e o carnaval são situações sociais que possibilitam a ocupação de um mesmo espaço por classes sociais e grupos diferentes, o que não significa entrosamento de fato. Isto ocorre porque Vila Isabel é formada por indivíduos bastante diferenciados e com experiências diversas e que, em certa medida, interagem, tanto no cotidiano como em momentos festivos, recreativos (penso, por exemplo, nas escolas de samba, bares, festas, funk) e rituais, como aqueles relacionados à religiosidade (igrejas católicas, evangélicas, terreiros de umbanda, casas espíritas), à política e às celebrações. Nesse movimento, as pessoas, orientadas por gostos e interesses pessoais e coletivos,

18 Esta é uma festa da religiosidade popular ligada às tradições católica e afro-brasileiras. Nestas últimas, no Brasil, São Cosme e Damião são associados aos ibejis, gêmeos amigos das crianças que realizariam o pedido que recebessem em troca de doces e guloseimas. Os fiéis oferecem doces e brinquedos às crianças no dia 27 de setembro, quando seu dia é celebrado. 
interagem e se evitam, abrindo possibilidade tanto de comunhão quanto de conflitos (Velho e Machado 1977; Velho 1994; 1997; Costa 1999; Cordeiro e Costa 1999).

Dessa maneira, nessa festividade, as pessoas ficavam entre os seus pares, o contato face-a-face com pessoas do outro grupo social ocorria nos momentos em que os integrantes da banda entregavam doces e comidas às crianças. Nesse cenário, os pertencimentos e as distinções foram marcadas, evitando o (con)fundir-se; por isso os membros da banda levavam seu estandarte e vestiam sua camiseta, demarcando uma identidade, como a de anfitrião. Ser anfitrião, nesse contexto, pode ser entendido dentro de um intricado sistema de trocas: dar, receber, retribuir (Mauss 1988 [1950]). Por uma via, o sistema de obrigações é estabelecido com os santos - São Cosme e São Damião. Por outra, o circuito da reciprocidade envolve os seus "outros", os moradores das favelas - as do "Complexo dos Macacos". Isto porque a dádiva tanto estabelece quanto mantém as relações sociais, por intermédio do circuito da reciprocidade. Dessa maneira, as oferendas distribuídas - brinquedos, comidas, doces - são as moedas de troca das dádivas alcançadas, como a cura de um ente ou o "sucesso" na carreira profissional, mas também a obtenção e manutenção do prestígio, como é possível perceber na fala de Seu Mariano:

Na primeira festa de São Cosme e Damião, colocamos à disposição das crianças 1500 saquinhos de doce, distribuição de brinquedos. Aí nos associamos com um dos diretores da banda [...], que ele é um comerciante muito bem-sucedido aqui em Vila Isabel e ele é que vem patrocinando, vamos dizer assim, a banda. Então, na última festa de Cosme e Damião, ele colocou várias atrações para as crianças, brinquedos, escorrega e ele bancou sozinho. E os doces foi a comunidade de Vila Isabel quem bancou, colocamos mais de 2500 crianças na rua.

\section{O "COMPLEXO DOS MACACOS"}

As crianças a quem Seu Mariano fez referência são aquelas que moram nas três favelas - Parque Vila Isabel, Pau da Bandeira e Morro dos Macacos - denominadas homogeneamente, por moradores e não moradores, como "Complexo dos Macacos". Do outro lado desta serra está situada a favela Morro do São João. Nas conversas com moradores do morro e em algumas músicas cantadas nos bailes funk em que participei, foi mencionada a rivalidade entre o São João e as favelas designadas genericamente de "Complexo dos Macacos". Essa rivalidade é expressa ainda na associação dos traficantes locais a facções criminosas opostas.

A história dessas favelas não consta em nenhum livro oficial, não fazem parte da história e da memória institucionalizadas. Um dos motivos pelos quais as favelas não são vistas como fazendo parte da memória e da história 
oficiais do bairro é que, na maioria das vezes, elas são entendidas como localizadas para além dos limites topográficos dos bairros em que estão situadas geograficamente, principalmente quando o tema é a violência - visto que as fronteiras são socialmente construídas e essas classificações e distinções estabelecidas num jogo de poder entre os moradores do bairro e os do morro. Nesse sentido é que Vida Luzia, moradora no bairro, naquela comemoração de aniversário de Vila Isabel, falou: “aqui é muito tranqüilo, não tem violência, a gente ouve uns tiros, à noite, no Morro dos Macacos e no Salgueiro, mas é lá, a gente não tem nada a ver com isso". Sua fala remete à não inclusão do Morro dos Macacos nos limites do bairro, pelo menos quando a referência é a "violência" e "uns tiros".

Isto ocorre, ainda, porque as favelas e o bairro, como "lugares reais e imaginados", abrem possibilidades para movimentos de inclusão e exclusão de parcelas da população, dependendo do que estiver em jogo. ${ }^{19}$ Nesse caso são a história e a própria identidade do bairro que correm o "risco de se contaminar" com o estigma que recai sobre a favela e sobre cada indivíduo ali inserido. Esse processo de estigmatização da favela, vista como locus de "problemas", emerge simultaneamente ao surgimento das primeiras favelas no final do século XX (Valladares 2005). Dessa maneira, não incluir nas obras bibliográficas sobre Vila Isabel os morros e a população que os habita revela o que se quer preservar.

Contudo, se a história e a memória do morro não estão nas obras legitimadas como as "verdadeiras" depositárias e transmissoras daquilo que foi oficializado sobre o bairro, elas estão na memória dos idosos, que narraram momentos de suas experiências nesse local. ${ }^{20}$ Essas narrativas foram colhidas por ocasião das comemorações dos 20 anos do Centro Comunitário, quando pude realizar entrevistas com 29 idosos, moradores desses morros. Por meio de suas narrativas, convocadas por minhas perguntas e por minha escuta, os idosos rememoraram e reconstruíram não apenas a história e o espaço onde vivem, mas suas próprias experiências inseridas nesse local, visto que "o espaço no qual estão emolduradas as memórias é fundamentalmente um espaço de interação" (Ferreira 2003: 221 ). Nesse espaço, os idosos ressemantizam objetos e ações, que, mesmo não existindo mais hoje, permeiam suas vidas.

19 Sobre a relação entre bairros e favelas no Rio de Janeiro, ver, entre outros, Zaluar (1985), Zaluar e Alvito (1998), Ribeiro e Lago (2001), Valladares (2005). Sobre a discussão antropológica a respeito de "bairros", da construção e reconstrução de suas fronteiras e história, ver, entre outros, os textos de Velho (1978 [1973]), Santos e Vogel (1981), Cordeiro e Costa (1999), Leite (2001) e Brito (1999; 2003).

20 Uma das primeiras tentativas de oficializar a história das favelas é o texto de Gaspar (2003), que aponta para o surgimento da primeira favela local, o Morro dos Macacos, em 192 I; o Parque Vila Isabel teria surgido em 1960, após o fechamento do Jardim Zoológico. Seu texto encontra-se numa coletânea organizada com o objetivo de "reconstruir a história desses bairros e favelas [da Grande Tijuca], resgatando a memória coletiva de sua população e examinando diferentes momentos e modos de relação entre moradores e moradoras dos dois tipos de espaços urbanos" (Santos, Leite e Franca 2003: 4). 
Em situações como esta, em que há ausência de material bibliográfico, os idosos tornam-se os guardiões das memórias sociais, tanto da própria família como de acontecimentos gerais da sociedade, passando pela história dos locais onde viveram. Esta memória é contextualmente ressignificada e moldada, ligando o indivíduo à realidade social construída por seu grupo. Os idosos não apenas guardam, mas transmitem seus conhecimentos, suas experiências de vida, as tradições culturais familiares e locais, que, dessa maneira, serão mantidas e reproduzidas posteriormente (Halbwachs 1990; Bosi 1979; Barros 1989).

Segundo Seu Mariano, morador do bairro, esta favela teria se formado quando "os antigos moradores da Fazenda dos Macacos, principalmente aqueles mais pobres, foram subindo o morro e aí começou a crescer o Morro dos Macacos".

Segundo alguns moradores, o nome do local, Morro dos Macacos, assim como a Fazenda, deve-se ao fato de ali terem existido muitos macacos. Tal nome, por vezes causa certo incômodo, por remeter ao preconceito frente aos negros, visto que, na sociedade brasileira, "macaco" é usado, muitas vezes, como termo pejorativo e acusatório contra os negros. Assim, numa reunião organizada pela Prefeitura e por uma ONG, realizada numa das salas do CIEP ${ }^{21}$ com vistas a discutir empreendimentos locais, alguns moradores presentes reclamaram que "aqui ninguém é macaco", referindo-se ao convite da reunião, que dizia: "II Fórum Econômico de Macacos". O coordenador do encontro redimiu-se: "aqui é o Parque Vila Isabel, Complexo dos Macacos".

Ao incômodo do nome do local, também Seu João Lucas, 89 anos, fez referência em sua entrevista, quando lhe perguntei o nome do local onde estávamos:

- O Centro mesmo é Morro dos Macacos. Mas antigamente o povo tinha preconceito. [...] Lá no fim dessa rua para cá tinha uma cerca de arame, $[\ldots]$ descia cercando aqui a comunidade para dizer que era Morro do Parque do Jardim. Tinha preconceito.

- E porque tinha preconceito de chamar de Macaco?, questionei.

- Alguém, os antigos daqui, cercaram para não ser Morro do Macaco.

Então, quando vem na televisão, ou no rádio, eles xingam tudo é de Morro dos Macacos mesmo.

Segundo Dona Anastácia, 66 anos, presidente do Centro Comunitário, o surgimento e o crescimento do Morro Parque Vila Isabel ocorreu por meio do loteamento do local pelos guardas e funcionários do Parque, responsáveis por

21 Os CIEP (Centro Integrado de Educação Pública) foram construídos durante o primeiro governo estadual de Leonel Brizola, na década de 1980. 
"não deixarem ocupar o morro", mas teriam sido "eles mesmos [que] ajudaram a encher o morro". Outras pessoas se referiram aos guardas do Parque.

A presidente, ao me narrar com bastante desenvoltura o desenvolvimento do morro, tinha também como intuito tornar oficial sua versão. A mesma história foi narrada a outro pesquisador, que encontrou ainda outras versões sobre a ocupação local (Souza 2004).

A forma como a própria Dona Anastácia conseguiu seu barraco no morro aponta para uma rede constituída por guardas florestais e trabalhadores da Prefeitura, que traziam para morar no local seus familiares, amigos e conhecidos. A partir dessa rede, segundo sua memória, o morro foi sendo "ocupado" e as favelas formadas:

O Pau da Bandeira era uma área que tinha donos, que se diziam donos dos terrenos ali, [...] mas que não eram verdadeiros donos, eles ocuparam a terra e se diziam donos. [...] Quando eu cheguei aqui tinha algumas pessoas que moravam, a maioria eram funcionários do Parque, eram os guardas florestais, pra não deixarem ocupar o morro mesmo [...]. As pessoas que vinham de fora, como eu que cheguei, comprei de um funcionário, que tinha um barraquinho aqui. Aí ele vendeu uma parte dele pra mim, arranjou uma briga, precisou fugir. E os outros eram guardas, trabalhavam no Parque e moravam aqui próximo mesmo, como quem tomasse conta, mas eles mesmos ajudaram a encher o morro.

Mediante sua narrativa é possível perceber que o morro foi sempre visto como tendo pessoas que "se diziam os donos da terra", "de uma área", e que não deixavam qualquer pessoa fazer barraco ali, apenas aqueles que faziam parte de sua rede de relações pessoais. Se na época em que chegou eram os guardas florestais, os funcionários do Parque e seus familiares que dividiam "o terreno, como se fosse uma herança", pois era "tudo parente" e eles tomavam conta", hoje é o principal traficante do local que é chamado pelos jovens e por alguns idosos de "dono do morro". Isso aponta para relações de poder, das quais dependem a entrada e a permanência da pessoa nesse espaço, pois tanto naquele tempo quanto hoje algumas pessoas "arranjavam uma briga" e "precisavam fugir".

Segundo os idosos entrevistados, a construção do morro ocorreu com a chegada e instalação de pessoas oriundas de diversos locais. Os "guardas”, ora municipais, ora florestais, se vissem, não deixavam as pessoas construírem seus barracos. Assim, segundo Dona Morgana, 61 anos, "todo mundo procurava mais o alto para os guardas não verem. Quando eles viam já tinha gente lá dentro, tinha criança dormindo $[\ldots]$ ".

Esses idosos estão, em sua maioria, há 50 ou mais anos no local e em suas narrativas colocam-se como desbravadores, visto que o local, em sua memória, 
"era só mato aqui, cobra, aquelas cobra bonita! Os guardas dormiam dentro do mato, a polícia dormia dentro do mato, cada um com sua carabina" (Dona Nalva, 89 anos, moradora há 76 anos).

Por terem passado por experiências diversas nesse local e conseguido chegar à velhice é que há espaço para certa nostalgia do passado, reconstruído no presente: "era sossegado, a gente se virava muito bem, agora tem tudo e a gente não tem sossego" (Morgana).

Esses idosos não consideram as suas primeiras habitações como casas, mas, sim, "barracos", feitos, segundo Seu Marcílio, 77 anos, de materiais como "tábua", "folha de lata", "pano" e "estuque", que segundo Seu João Lucas é "barraco de barro, prega-se as ripas assim e amassa o barro e faz as paredes de barro".

Segundo Dona Guilhermina, 74 anos, "a Prefeitura desmanchava muita casa nos morro[s] [...]. Desmanchava a casa em cima de tudo, as coisas ficavam lá, $[\ldots]$ quebravam tudo [...]". Por isso, segundo ela, os "barracos" eram construídos à noite: "quando a gente acordava, já tinha um barraquinho, a gente não sabe nem de onde veio, mas eles faziam”.

Os idosos contaram, ainda, que não havia água, luz elétrica no morro ou fogão a gás - este era a lenha ou a querosene. Para obterem água tinham de encher as "latas" e as trazerem na "cabeça". Os locais recordados em que iam buscar água eram a "Borda do Mato", onde também lavavam as roupas, a "fábrica de água sanitária" e o "Corpo de Bombeiros, lá no Grajaú". A luz era obtida com "lampiões" e "lamparinas". Posteriormente, alguns moradores passaram a ter luz elétrica e "cediam", "alugavam" àqueles que não tinham.

Fazendo comparações com o passado, quando chegaram à favela, os idosos consideram que hoje está "muito melhor". Fizeram referências a melhorias ocorridas nos governos estaduais de Carlos Lacerda ${ }^{22}$ (década de 60) e de Brizola $^{23}$ (década de 80) e, dos últimos tempos, ao Favela-Bairro II - Programa de Urbanização de Assentamentos Populares (Proap) da Prefeitura Municipal do Rio de Janeiro -, que tem como proposta "integrar a favela à cidade, dotando-a de toda infra-estrutura, serviços e equipamentos públicos e políticas sociais”

22 Carlos Lacerda (1960-1965) foi eleito o primeiro governador do recém-criado Estado da Guanabara, em 1960, pela UDN. Em seu governo, as favelas eram vistas como um "problema político", sobre o qual incidiram duas vertentes de ações: por um lado, a remoção; por outro lado, a urbanização de algumas delas. Nesse período, foi incentivada a criação de Associações de Moradores para organização interna.

23 Leonel Brizola foi eleito governador do Rio de Janeiro duas vezes (1982 e 1990), pelo PDT (Partido Democrático Trabalhista), do qual foi fundador. Conforme Burgos (1998: 42), "o governo Brizola desenvolveria uma agenda social especialmente voltada para as favelas do Rio de Janeiro", pela qual "esperava definir uma nova conduta para as polícias civil e militar perante os excluídos, baseada no respeito a seus direitos civis". Mediante esta política, seu governo recebeu diversas críticas por determinados setores da sociedade, que consideram que ele contribuiu para o incremento da violência e para a instalação do tráfico nas favelas, sendo acusado de "defensor de bandido". 
(Prefeitura... 2003). Nesse local, o programa construiu uma praça, um conjunto de casas, um shopping, asfaltou ruas e financiou "projetos sociais" voltados para crianças, jovens e idosos.

Segundo a presidente do Centro Comunitário, foi de fundamental importância, para obtenção das melhorias, a existência e atuação da Associação de Moradores, que reivindicava e pressionava o governo e os políticos em busca dessas melhorias. A associação organizava também "mutirões";24 por exemplo, ela "comprava cano pra gente encanalizar o esgoto, o morador fazia, pra melhorar a água”.

Devido a estas melhorias e ao aumento do número de moradores é que alguns idosos, como Seu Marcílio, consideram o morro "uma cidade, por causa da modificação, eu não considero mais favela, pra mim é uma cidade". Uma "cidade" feita de "casa[s] de dois, três andar[es]", o que para Seu João Lucas, 89 anos, “é uma beleza”. Para Dona Guilhermina, 74 anos, são “casas bonitas, onde ninguém paga aluguel, porque quase todas casas são próprias mesmo".

O número de moradores do morro varia de 11 mil a 30 mil, conforme, respectivamente, o IBGE e a presidente do Centro Comunitário. Esta variação dá-se conforme a fonte e as intenções de quem fornece os números.

\section{O ANIVERSÁRIO DE 20 ANOS DO CENTRO COMUNITÁRIO}

Neste momento, passo a abordar a construção das memórias e das histórias do Centro Comunitário de um dos morros do "Complexo dos Macacos". No dia anterior à festa de comemoração de 20 anos da entidade, a sua presidente, Dona Anastácia, fez inúmeras correções em sua entrevista, realizada vinte dias antes, na qual havia me contado sua história de liderança no local. Nessas “correções”, por exemplo, ela trocou a palavra tráfico por violência, alterou fatos que considerou impróprios para os interessados lerem, como a destituição de um dos presidentes da Associação de Moradores. Ela desejava que esta história fosse narrada na festa e ficasse disponível à leitura. A tentativa de construir uma narrativa que ligasse a história do morro à sua história de liderança é, também, um esforço de legitimação de sua posição e de seu poder, como liderança política local. Nesse sentido, como uma "mulher política”, Dona Anastácia está permanentemente lançando mão de estratégias de sobrevivência, adaptando-se às mudanças sociais e negociando sua posição.

A comemoração ocorreu na praça Barão de Drummond, área central de Vila Isabel, em julho de 2003, durante a tarde e a noite. Participaram do evento os

24 Mutirões são mobilizações coletivas para construção de casas, ou escolas, baseadas na mútua ajuda gratuita e onde todos são beneficiários da obra. No período referido pelos idosos, era mediante o sistema de mutirão que eram construídas as casas e realizadas as obras na favela. 
trabalhadores e freqüentadores do Centro Comunitário, moradores do morro e do bairro, políticos, dirigentes de ONG, entre outros.

A entidade montou diversos stands - doados por uma universidade particular-, onde ficaram expostos os cartazes das atividades do Centro e onde alguns trabalhadores atenderam ao público, como a escola de informática. Atrás dos stands estavam os quiosques (que fazem parte da paisagem local), onde alguns funcionários, companheiros e amigos destes ficaram bebendo cerveja, conversando, entre uma atividade e outra. Essa dimensão festiva, de comemoração, seguiu-se durante o evento, concomitantemente com as dimensões ritual e espetacular.

A aparência de Dona Anastácia, contrastando com a dos funcionários, trabalhadores e freqüentadores da entidade, para além de indicar seu pertencimento religioso (batista), simboliza a imagem da mulher "guerreira, batalhadora", como uma de suas filhas a descreveu no evento. Esta mulher atrelou a sua própria história de ascensão social à expansão do centro. E, apesar do crescimento dos recursos materiais e financeiros e da importância política da entidade, ela não demonstra, pela simplicidade de suas roupas, de sua aparência, ter se apropriado desses recursos. Pelo contrário, compartilha e retribui, mediante os próprios "projetos sociais", as dádivas alcançadas com seu séquito, o que a legitima e a sustenta em sua posição de liderança.

Elena, uma das filhas de Dona Anastácia, atuou como mestre-de-cerimônias do evento e narrou a história de fundação da entidade: "A presidente do Centro Comunitário, Dona Anastácia, é uma pessoa que fundou o Centro Comunitário, começou com uma escolinha aqui na comunidade, na sala da casa dela e o trabalho foi crescendo [...] e hoje nós estamos com 20 anos."

A fala de Elena, como uma ação social, proferida e repetida inúmeras vezes, no contexto desta autocelebração, junto a outras narrativas, agradecimentos e apresentações, evidencia elementos da dimensão ritual deste evento. As expressões usadas por Elena serviam, ao mesmo tempo, como uma consagração à posição alcançada por Dona Anastácia, um incitamento à emoção coletiva, um reforço do sentimento de pertença e dos elos sociais entre aqueles que trabalham e participam de alguma atividade no Centro - pelo menos destes.

A presença e a ação dos participantes, como as flores ofertadas à Dona Anastácia pelos membros de uma ONG (que também atende aos moradores do morro), evidenciam a inclusão (e o pertencimento) de Dona Anastácia e do Centro Comunitário num circuito em que recursos sociais (o público que dá estofo aos projetos), políticos (os projetos sociais) e econômicos (os financiamentos) estão em disputa. Junto a esses recursos, e próprios aos circuitos de trocas, são disputados prestígio e status social, tão caros à manutenção da autoridade. Essas pessoas trazem o reconhecimento a esta líder, legitimando e reforçando seu poder. 
Neste contexto é que ganha sentido, numa quarta-feira, o Centro Comunitário postar-se em festa, em meio ao ritmo do trabalho, para autocelebrar-se, para rememorar e exaltar uma história (re)construída. O propósito da autocelebração era também conquistar novos adeptos (novos "parceiros" e financiadores), bem como construir e reforçar identidades, posições e prestígio sociais.

Elena anunciava as atrações, que eram as oficinas realizadas cotidianamente no Centro. Entre uma apresentação e outra, fazia um pequeno discurso que evidenciava, entre outros aspectos, o propósito do evento:

[viemos para a] rua dar visibilidade ao trabalho que a gente faz aqui na comunidade. [...] Nossos vizinhos!, é hora da gente fazer uma integração entre o morro e o asfalto e mostrar que nós temos sonhos e nós queremos realizá-los! Nós somos parte dessa nação, dessa comunidade, desse bairro.

Sua fala ritual, repetida do início ao final do evento, marca a subversão simbólica do espaço: a praça - no centro do bairro, destinada, primeiramente, aos seus moradores do "asfalto" - é "tomada de assalto" e "dividida, também, com todo mundo" pelos moradores da "favela". Essa súbita investida assume o sentido de buscar desarranjar as representações que os moradores do "asfalto" alimentam em relação aos da "favela", das quais surgem as acusações de "poluição" e de "contaminação" (Douglas 1976), que tornariam o Rio de Janeiro uma "cidade partida".

Um agente importante na difusão dessa imagem é a mídia, que, ao transmitir a notícia, muitas vezes isolando o fato e mostrando-o de forma espetacular, veicula uma determinada visão da realidade que está mais relacionada com as suas finalidades de informar e de lucrar, criando e suprindo, ela mesma, uma demanda por determinado assunto (Jankowski 1991a; 1991b). A mídia é uma fonte de informação para a conformação do senso comum, que é composto por percepções sobre determinado assunto, construídas a partir das experiências subjetivas das pessoas.

Nessa (di)visão, que toma a "violência" como ponto de interseção da cidade, as favelas são vistas como homogêneas, simbolizando a ilegalidade, fonte de muitos problemas e de insegurança; o "asfalto" também é visto homogeneamente, como símbolo da legalidade, da ordem, da solução e do medo. Medo esse que inclui ser "tomado de assalto" pelos moradores das favelas. O contraste passa, ainda, por uma disputa de classe, de visões de mundo e estilos de vida. Dessa maneira, recai sobre as favelas um estigma, que torna seus moradores "desacreditados" (Goffman 1988), dado que elas são tomadas como o local do crime, da violência, e o habitat das "classes perigosas".

Esta ação ritual é extremamente significativa, visto que a relação entre as favelas e os bairros circunvizinhos passa a ser entendida e experienciada como 
envolta em conflitos e acusações por parte dos moradores dos bairros e pela mídia, advindos, principalmente, pelo destaque que dão às atividades do tráfico e uso de drogas. Essas ações seriam as responsáveis por grande parte das cenas de violência ocorridas na cidade, tanto no interior das favelas - pela briga entre traficantes rivais e atuação da polícia - quanto fora delas - pelos tiros, balas perdidas e assassinatos.

A tentativa de resolução desses conflitos apresenta-se mediante a execução de atividades civilizatórias (as oficinas e os projetos), realizadas cotidianamente no Centro Comunitário e apoiadas por diversas instituições e personalidades do "asfalto".

A fala de Elena, durante o evento, deixa antever que essas injunções são assimiladas tanto na favela quanto fora:

Muita gente aqui de Vila Isabel, que mora aqui no asfalto, não conhece muito bem a nossa comunidade e, às vezes, tem até uma falsa impressão do que acontece ali! Pensa que é só tiro, violência e droga, mas não, ali no morro, a gente tem sonhos e a gente está sabendo realizar esses sonhos [...] A gente quer respeito e é isso que a gente quer com essa comemoração aqui: mostrar que nós somos iguais a qualquer outro cidadão brasileiro [...].

Nessa reivindicação de "igualdade", mais do que clamar pela consecução de alcançar uma igualdade de direitos, está implícita uma disputa por recursos políticos, sociais, econômicos e de prestígio. Essa concorrência acontece numa configuração de poder em que os recursos são escassos e por isso é necessário "merecê-los" (Borges 2003).

No evento, essa disputa também foi revelada quando do lançamento "simbólico" de "O resgate da memória de Vila Isabel", uma compilação de textos publicados na internet e dados retirados de outros livros sobre a história do bairro e do morro.

Esse "livro", segundo seu idealizador, o professor de informática (morador do morro e ex-aluno do Centro), é um movimento para mostrar o morro em diversas nuanças, seus empreendimentos, "as coisas boas que tem aí", como os poetas, a escola de informática, entre outros; buscava, desse modo, romper com o conhecimento produzido pela mídia, baseado em episódios isolados, que colaboram para a visão do senso comum de que ali só existe violência. Pelo empenho em publicar o livro, percebi a existência de uma luta, principalmente simbólica, entre os moradores do morro e do bairro, pela produção, imposição e legitimação da visão e di-visão de mundo desses moradores, expressa aqui em qual história e qual memória será institucionalizada (Bourdieu 1989). Essa disputa busca legitimar também os representantes desses grupos, quem pode representar quem e quando, quem está autorizado a narrar as histórias e fixar as memórias que serão as oficiais. 
O livro compilado compete com aquela produção de livros, como visto acima, apoiada pela classe média local. Esses livros (muitos dos quais foram utilizados pelo professor para compor o seu) refletem o esforço deste setor, pelo menos, para construir e manter uma identidade do bairro, manifestada na própria construção da história oficial do local e de áreas desse local, e neles não é mencionada a expressão "favela" ou a sua existência. A sua invisibilidade relativa é outro fragmento desse caleidoscópio que contribui para tensionar ainda mais as relações sociais entre os moradores dessas duas localidades.

Essa invisibilidade relativa também apareceu na conversa com a funcionária da IX RA (Região Administrativa). Ela somente se referiu às "comunidades" para citar o nome das associações de moradores. E, nesse momento, ela me advertiu para eu não adentrar "muito longe do portão principal" no parque em frente, "porque o pessoal da comunidade desce e fica ali, às vezes, até armados".

Se a possibilidade de encontro com os moradores da "favela" por quem não mora nesse espaço causa certa tensão, em outras situações, a relação entre os moradores das duas localidades ganha outras tonalidades, como naquela festa de São Cosme e São Damião.

É nesse contexto que a demonstração pública das atividades desenvolvidas no Centro Comunitário (as oficinas e os projetos) para moradores, instituições e personalidades que representam o "asfalto" e as apóiam expressa seu cunho civilizatório e acena com uma possibilidade de resolução dos conflitos entre os moradores de ambas as localidades.

Entre as apresentações (coral, percussão, poesia, teatro, entre outras), Dona Anastácia discursou, agradecendo aos "parceiros" do centro (entidades que financiam os projetos e pessoas que desenvolvem algum trabalho) e às pessoas que, por sua posição e prestígio social (como vereadores, administrador regional) realçam e reforçam o status social dela. Por outro lado, por serem políticos é interessante que mantenham estreita relação com uma liderança do morro, que pode arregimentar, ou, pelo menos, influir nos votos. E o reconhecimento manifestado pela presidente da entidade colabora para o fortalecimento desse elo social.

O evento encerrou-se ao som da banda trazida pela Prefeitura.

\section{CONSIDERAÇÕES FINAIS}

Ao longo deste artigo analisei as histórias e memórias oficiais e não oficiais do bairro de Vila Isabel e das favelas locais, que emergiram de uma série de eventos comemorativos. Estes, ainda, atuaram na construção de identidades sociais dos moradores e, nas narrativas relatadas, foram revelados os elementos pelos quais os moradores de Vila Isabel se distinguem dos "outros" bairros, incluem e excluem setores, conforme o que está em jogo. A história do morro, ignorada na história e na memória oficial do bairro, foi acionada pelos seus moradores, 
havendo o intuito, em especial da presidente do Centro Comunitário, de fixar essa história, oficializando-a conforme sua versão dos acontecimentos. Portanto, esses foram momentos de disputa pela legitimidade para narrar a história e a memória dessas localidades.

A partir daí foi possível perceber o contexto no qual as relações sociais entre os moradores do bairro e os do morro são estabelecidas. Na relação entre o "asfalto" e, sua localidade oposta, a "favela", o que está sendo enfatizado é o conflito. Essa terminologia - vinda de fora - busca, na representação da "cidade partida" (Ventura 1994), os termos para colocar em conflito aberto os moradores dessas duas localidades. O ponto de interseção da cidade, atualmente, é "a violência" - categoria construída para produzir a "cidade [bi]partida"; noutros tempos já foi a feiúra, as doenças que a favela traria, quando, então, se propôs a sua erradicação. Quando professada, esta dicotomia abre caminho fértil à implantação - e dá sentido à sustentação - de práticas civilizadoras por parte de entidades do "asfalto", que visam manter essa parte da população sob controle, visto que sob o arsenal descortês do tráfico não logram êxito.

A análise de eventos não cotidianos, como as festas, auxilia na compreensão daquilo que ocorre no dia-a-dia dos moradores do bairro e dos freqüentadores, trabalhadores e funcionários do Centro Comunitário. Abordá-los a partir do referencial teórico sobre rituais ajuda na percepção de situações de campo que, muitas vezes, ficariam obscurecidas.

Esses eventos, inseridos em um processo social, revelam as prolongações dos fios de uma teia em que os sujeitos estão emaranhados nas situações sociais nas quais interagem.

Ressalto, ainda, que colocar os holofotes sobre as festas realça não apenas os fatos acontecidos nesses momentos, mas, como formas de ação e comunicação, o idioma ritual descortina diversos pequenos circuitos de trocas, às vezes concorrentes, que se entrecruzam, formando um grande potlatch em que dádivas são ofertadas, recebidas e retribuídas.

As coisas trocadas, mais do que objetos materiais, são pessoas, poder, autoridade, status e prestígio sociais, formam uma tessitura na qual sujeitos e pertenças são distinguidos, o elo social é reforçado e novos adeptos são encontrados. Revelam, ainda, um exercício intenso de sociabilidade.

Mediante essas comemorações, as histórias e memórias oficiais são reforçadas e, muitas vezes, cristalizadas. No entanto, elas abrem espaços para a emergência de histórias e memórias não oficiais. 


\section{BIBLIOGRAFIA}

ABREU, Maurício, 1997, A Evolução Urbana do Rio de Janeiro. Rio de Janeiro, Iplanrio, 3. ${ }^{\text {a ed. }}$ ANUÁRIO DE VILA ISABEL 95, 1995, Rio de Janeiro, Oceanic Consultoria e Treinamento, ano $1, \mathrm{n}^{\circ} 1$.

ARAGÃO, Nilde Hersen, 1997, Vila Isabel: Terra de Poetas e Compositores. Rio de Janeiro, Conquista.

BARros, Myriam Moraes L., 1989, "Memória e família”, Estudos Históricos, 2 (3): 29-42.

BLANC, Aldir, 1996, Vila Isabel: Inventário da Infância. Rio de Janeiro, Relume-Dumará e RioArte.

BORGES, Antonádia, 2003, Tempo de Brasília: Etnografando Lugares-Eventos da Política. Rio de Janeiro, Relume-Dumará e NUAP/UFRJ.

BORGES, Delane, e Marilane da Silva BORGES, 1987, A Vila de Isabel e Drumond a Noel. Rio de Janeiro, s/ed.

BOSI, Ecléa, 1979, Memória e Sociedade: Lembranças de Velhos. São Paulo, Edusp.

BOURDIEU, Pierre, 1989, O Poder Simbólico. Rio de Janeiro, Bertrand Brasil.

BRITO, Joaquim Pais, 1999, “O fado: etnografia na cidade”, em Gilberto Velho (org.), Antropologia Urbana: Cultura e Sociedade no Brasil e em Portugal. Rio de Janeiro, Jorge Zahar Editor, 24-42.

— — 2003, "A cidade exposta", em Graça Índias Cordeiro, Luís Vicente Baptista e António Firmino da Costa (orgs.), Etnografias Urbanas. Oeiras, Celta Editora, 43-51.

BURGOS, Marcelo Baumann, 1998, “Dos parques proletários ao Favela-Bairro: as políticas públicas nas favelas do Rio de Janeiro”, em Alba Zaluar e Marcos Alvito (orgs.), Um Século de Favela. Rio de Janeiro, FGV, 25-60.

CORDEIRO, Graça Índias, e António Firmino da COSTA, 1999, "Bairros: contexto e intersecção”, em Gilberto Velho (org.), Antropologia Urbana: Cultura e Sociedade no Brasil e em Portugal. Rio de Janeiro, Jorge Zahar Editor, 58-79.

COSTA, António Firmino da, 1999, Sociedade de Bairro: Dinâmicas Sociais da Identidade Cultural. Oeiras, Celta Editora.

COSTA, Maria Alice Antunes, 2003, "Sinergia e capital social na construção de políticas sociais: a favela da Mangueira no Rio de Janeiro”, Revista Sociologia e Política, 21: 147-163.

DOUGlas, Mary, 1976, Pureza e Perigo. São Paulo, Perspectivas.

FERREIRA, Maria Letícia M., 2003, "Memória e velhice: do lugar da lembrança”, em Myriam Moraes Lins de Barros (org.), Velhice ou Terceira Idade? Rio de Janeiro, FGV, 3. ed., 207-222.

GASPAR, Márcia Vianna, 2003, "A Vila de Isabel, Amélia e Drumond”, em Alexandre Mello Santos, Márcia Pereira Leite e Nahyda Franca (orgs.), Quando Memória e História se Entrelaçam: A Trama dos Espaços na Grande Tijuca. Rio de Janeiro, Ibase, 53-62.

GERSON, Brasil, 1959, História das Ruas do Rio de Janeiro. Rio de Janeiro, Prefeitura do Distrito Federal e Secretaria Geral de Educação e Cultura, 3. ${ }^{\mathrm{a}}$ ed.

GOFFMAN, Erving, 1988, Estigma: Notas sobre a Manipulação da Identidade Deteriorada. Rio de Janeiro, Guanabara.

HALBWACHS, Maurice, 1990, A Memória Coletiva. São Paulo, Vértice.

JANKOWSKI, Martín Sánchez, 1991a, “In the organization”, em Martín Sánchez Jankowski, Islands in the Street: Gangs and American Urban Society. Berkeley e Los Angeles, University of California Press, 63-100. 
— $1991 \mathrm{~b}$, "The media and gangs: image construction and myth management”, em Martín Sánchez Jankowski, Islands in the Street: Gangs and American Urban Society. Berkeley e Los Angeles, University of California Press, 284-310.

LeITe, Márcia da Silva P., 2001, Para Além da Metáfora da Guerra: Percepções sobre Cidadania, Violência e Paz no Grajaú, um Bairro Carioca. Rio de Janeiro, UFRJ, tese de doutorado em sociologia.

LEROI-GOURHAN, André, 1983, "Memória em expansão", em André Leroi-Gourhan, O Gesto e a Palavra (2). Lisboa, Edições 70, 57-67.

LUCAS, Maria Elisabeth, 1994, “Identidade sonora”, em Sergius Gonzaga (org.), Nós os Gaúchos (2). Porto Alegre, EdUfrGS, 139-143.

MAUSS, Marcel, 1988 [1950], Ensaio sobre a Dádiva. Lisboa: Edições 70.

—_, 1999 [1929], "A alma, o nome e a pessoa”, em Marcel Mauss, Ensaios de Sociologia. São Paulo, Perspectiva.

MÁXIMO, João, e Carlos DIDIER, 1990, Noel Rosa: Uma Biografia. Brasília, UnB (Linha Gráfica Editora).

PICCOLO, Fernanda Delvalhas, 2006a, Sociabilidade e Conflito no Morro e na Rua: Etnografia de um Centro Comunitário no Bairro de Vila Isabel. Rio de Janeiro, Museu Nacional/Universidade Federal do Rio de Janeiro, tese de doutorado em antropologia social.

— favela", em Heitor Frúgoli Jr., Luciana Andrade e Fernanda Áreas Peixoto (orgs.), As Cidades e Seus Agentes: Práticas e Representações. São Paulo, EdUSP, 330-352.

POLLACK, Michel, 1989, "Memória, esquecimento e silêncio”, Estudos Históricos, 2 (3): 3-15.

PORTELLI, Alessandro, 1998, "O massacre de Civitella Val Di Chiana (Toscana, 29 de junho de 1944): mito e política, luto e senso comum”, em Marieta de Moraes Ferreira e Janaína Amado (orgs.), Usos e Abusos da História Oral, Rio de Janeiro: FGV, 2. a ed., 103-130.

PREFEITURA DO RIO DE JANEIRO, 2003, "Das remoções à Célula Urbana: evolução urbano-social das favelas do Rio de Janeiro”, Cadernos da Comunicação. Rio de Janeiro, Secretaria Especial de Comunicação Social, Prefeitura da Cidade do Rio de Janeiro.

RIBEIRO, Luiz César de Queiroz, e Luciana Corrêa LAGO, 2001, "A oposição favela-bairro no espaço social do Rio de Janeiro", São Paulo em Perspectiva, 15 (1): 144-154.

RICO, Elisabeth de Melo, 2004, "A responsabilidade social empresarial e o Estado: uma aliança para o desenvolvimento sustentável”. São Paulo em Perspectiva, 18 (4): 73-82.

SANTOS, Alexandre Mello, Márcia Pereira LEITE, e Nahyda FRANCA (orgs.), 2003, Quando Memória e História se Entrelaçam: A Trama dos Espaços na Grande Tijuca. Rio de Janeiro, Ibase.

SANTOS, Carlos Nelson F., e Arno VOGEL (orgs.), 1981, Quando a Rua Vira Casa. Rio de Janeiro, IBAM/FINEP, 2. ${ }^{\text {a }}$ ed.

SILVA, Helenice Rodrigues, 2002, “Rememoração'/comemoração: as utilizações sociais da memória”, Revista Brasileira de História, 22 (44): 425-438.

SOUZA, Rogério Ferreira, 2004, Tecendo o Passado: Memórias da Favela Morro dos Macacos, Zona Norte do Rio de Janeiro. Rio de Janeiro, Unirio, dissertação de mestrado em memória social.

SUlPINO, Maria Patrícia L., 2002, "A construção do nordeste nas músicas de forró”, Conceitos, 5 (7): 108-112.

VAlladares, Licia do Prado, 2005, A Invenção da Favela: Do Mito de Origem ao Favela.com. Rio de Janeiro, FGV. 
VELHO, Gilberto, 1978 [1973], A Utopia Urbana: Um Estudo de Antropologia Social. Rio de Janeiro, Jorge Zahar Editor, 3. ${ }^{\mathrm{a}}$ ed.

—, 1994, Projeto e Metamorfose: Antropologia das Sociedades Complexas. Rio de Janeiro, Jorge Zahar Editor.

—, 1997, Individualismo e Cultura: Notas para uma Antropologia da Sociedade Contemporânea. Rio de Janeiro, Jorge Zahar Editor, 4. ${ }^{\mathrm{a}}$ ed.

VELHO, Gilberto, e Luiz Antônio MACHADO, 1977, "Organização social do meio urbano", Anuário Antropológico 76. Rio de Janeiro, Tempo Brasileiro, 71-82.

Ventura, Zuenir, 1994, Cidade Partida. São Paulo, Companhia das Letras.

ZAlUAR, Alba, 1985, A Máquina e a Revolta: As Organizações Populares e o Significado da

Pobreza. São Paulo, Brasiliense.

ZALUAR, Alba, e Marcos ALVITO (orgs.), 1998, Um Século de Favela. Rio de Janeiro, FGV.

Memories, stories and social representations of the district of Vila Isabel and one of its slums (RJ, Brazil) - Fernanda Delvalhas Piccolo - Instituto Federal de Educação, Ciência e Tecnologia do Rio de Janeiro (IFRJ) • fernanda_piccolo@uol.com.br

Based on an ethnography carried out in a community center in Morro dos Macacos, located in Bairro de Vila Isabel, a district in the Northern section of Rio de Janeiro city (Brazil), the present article is about the history and memories of that slum and neighborhood. It examines some events that reinforce its official history and memory or emphasize other stories and memories, different or alike. Those events are interesting symbolical expressions of individuals and groups, for they give visibility to social networks, since they reinforce a sense of belonging to a group and create social links. They are also important for contributing to create stories and memories - official and unofficial - that build social identities and representations that guide its inhabitants' practices.

KEYWORDS: slum, neighborhood, social identities, social memory, social networks, urban anthropology. 